\title{
The Value of Innovation in Nanotechnology
}

\author{
Jan Vlachy \\ Czech Technical University in Prague \\ Kolejni 2637/2a, 16000 Praha 6, Czech Republic \\ E-mail.jan.vlachy@cvut.cz
}

cross $^{\text {ref }}$ http://dx.doi.org/10.5755/j01.ee.28.5.16770

This paper addresses the highly current topic of using quantitative economic methods to support rational investment decision-making in the domain of technological innovation. Such investments are characterized by a high degree of exogenous and endogenous uncertainty combined with complex feedbacks, making conventional capital budgeting techniques inadequate. It introduces a comprehensive valuation model developed for the Shyman (Sustainable Hydrothermal Manufacturing of Nanomaterials) project, which researched and implemented new technologies in nanomaterial production and application. This represents a highly innovative and complex industry in all life cycle stages, making it a perfect candidate for research. The model combines various analytical methods, including a recursive form of life cycle costing (LCC), as well as statistical simulation (Monte Carlo) and real options, and addresses valuation from the perspective of a new end-product, as well as that of the production facility investor. A high Net Advantage to Innovating (NAI) has been identified in the industry. This result is strongly biased in favour of end-product innovators. Nevertheless, the hydrothermal synthesis-based nanomaterial production process benefits from its high degree of flexibility, i.e. option to switch, with a significant value premium arising due to outsize dynamics and uncertainty in the nanoindustry. Experience gained through this research can be extended to other cases of value-based analysis related to innovation.

Keywords: Net Advantage to Innovating, Value-Based Management, Capital Budgeting, Life Cycle Costing, Statistical Simulation, Real Options.

\section{Introduction}

Over the last decade, nanomaterials and their applications have become a rapidly growing global industry, both in scale and diversity. A study by Hansen et al. (2016) illustrates the increase in registered nanoproducts in Europe, growing from just 54 in 2005 to 1,814 in 2014, with more recent figures from the same database indicating 2,231 products in 2015. Market research by RNCOS (2015) projects a global nanotechnology market growth rate of 17.5 $\%$ through 2022 , which is broadly consistent with other sources. At the same time, numerous different technologies with diverse characteristics are being used by both specialized and commodity firms, as well as the end-product manufacturers themselves, to produce the essential nanoparticle components (Stieberova et al., 2014).

Shyman (Sustainable Hydrothermal Manufacturing of Nanomaterials) was a large EU project (2012-2016) coordinated by the University of Nottingham, comprising research, development, production and application of nanomaterials (Shyman, 2016a). The project was unique in that, through its academic and business partners from eleven European countries (Shyman, 2016b), it subsumed the complete product life cycle, including research in materials and production technology, as well as the development, implementation and review of pertinent applications. This facilitated a holistic approach to analyses with strategic focus, including total impact assessments, both environmental life cycle assessments (Ticha et al., 2016), and economic, derived from life cycle costing of particular products.
This paper describes the structure and selected results of a comprehensive economic model, developed within the scope of the project, which helped identify and assess the essential value drivers at different stages of the product life cycle. Besides supporting actual decision-making, the research made on the project contributes to the highly current and meaningful topic of value-based approach to innovation, which has, as yet, tended to be analysed primarily on a purely qualitative, comparative or conceptual basis (Christensen, 1997; Day, 2007; Molloy et al., 2011; Treacy, 2012; Arend, 2013), rather than as part of rigorous strategic management based on contemporary financial theory (Vlachy, 2009).

The problem is posited as follows: A plant is being designed, under a special-purpose spin-out business unit of the University of Nottingham, that will allow full-scale production of a wide range of nanoparticle-based chemical substances. Its patented technology (Dunne et al., 2014; Munn et al., 2015) is characterized by a unique production flexibility, as well as economies of scale. Namely, the same equipment will have the capability to produce chemicals with diverse composition, including substances that are currently supplied only by relatively very inefficient and disparate laboratory-scale operations (Stieberova et al., 2014). At the same time, other materials can be readily purchased from industrial producers that use a range of different technologies, and can thus be considered commodity (Charitidis et al., 2014). The facility should be commercially sustainable, either on a stand-alone basis, or under licensing arrangements; nevertheless, numerous uncertainties have to be taken into account regarding the future development of the 
nanoparticle wholesale market, as well as the potential for their use in distinct end-product applications, some of which exist only at a very early stage of development.

The model presented in this paper is original in that it combines several different methodological approaches. Fundamentally, it resolves the issue of project valuation by means of simulating an optimal product portfolio strategy for the nanomaterials manufacturing plant, deriving projections of demand from a combination of life cycle cost and competitive price-setting considerations. The life cycle cost (LCC) approach (Woodward, 1997; Boussabaine \& Kirkham, 2004; Dhillon, 2010) is used recursively to obtain benchmark valuations for innovative products, which are either non-existent in the market, or lack a commercial history. It also represents the distinctly flexible characteristic of the production technology as a real option to switch (Park and Herath, 2000; Schwartz and Trigeorgis, 2001). Emblesvag (2003) does combine life cycle costing with statistical simulation, but takes a completely different approach, with different objectives.

Organization of the paper reflects two distinct issues the model needs to resolve. First, future demand for particular nanoparticles will be driven by the demand for end-products which will be using them to enhance utility for end-users. Many of these products are not yet established in the market and their valuations can thus only be implied from those of existing and potentially competing products. This is initially investigated using an LCC model and its recursive application, leading to the determination of the Net Advantage to Innovation measure. Second, the innovation process is characterized by an extremely high degree of uncertainty and dynamics, with the system featuring significant feedbacks. This requires solving the nanoparticle production plant valuation as a capital budgeting problem using statistical simulation. The final Results section comprises analyses of two particular coating-application cases and outputs of the production plant valuation model.

\section{Research Methods}

\section{Assessing the Net Advantage to Innovation}

A number of LCC models for sundry applications have been described in literature over several decades (Gupta and Chow, 1985; Artto, 1994; Rebitzer \& Seuring, 2003; Dhillon, 2010). Azzopardi et al. (2011) have actually used it to assess the use of new materials in solar panels, which currently seems to be one promising line of nanomaterial applications (Sun et al., 2015). However, the present problem requires a specific approach, that benchmarks the newly considered product against either a) an existing comparable product, or b) a different means of satisfying a utility by the end-user, with neither utilizing the new material. The valuation thus stems from a particular application of target costing relative to a functional unit (Carlsson et al., 2007), rather than conventional unit-based calculation (Sakurai, 1989; Clifton et al., 2003).

In this application, we use a three-stage life cycle model, consisting of the material production stage, the endproduct manufacturing stage and the end-product use stage, calibrated to a functional unit. This is illustrated by Figure 1. Examples of nanomaterials benchmarked at either their projected market price $\left(P_{\mathrm{X}}\right)$ or a life cycle cost model-based price $\left(P_{\mathrm{Y}}\right)$ are shown therein, the latter price being determined recursively as a cost component of a new product (A), compared with a different and currently marketed product (B), satisfying the same functional utility, as in Figure 1.

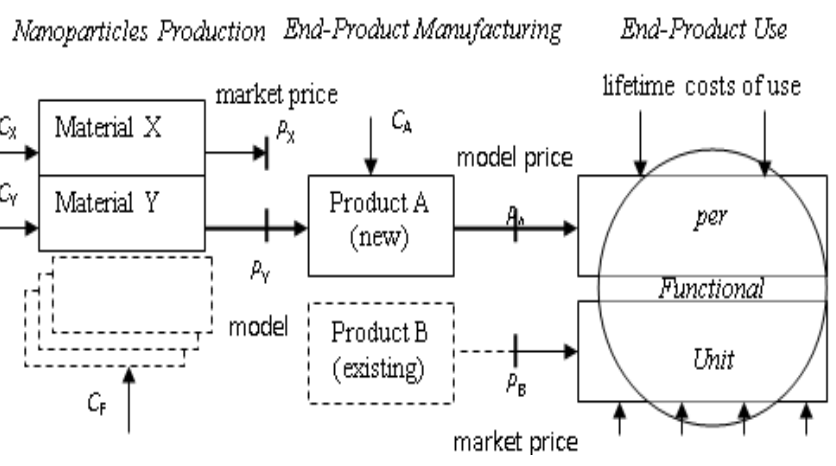

Figure 1. Deriving implied model prices using LCC

Actual cases being considered include various costbenefit structures in the end-product use stage. Typically, they can be generalized as various combinations of a) different product costs, b) different useful lives, c) differences in one or more performance measures, d) differences in maintenance costs or other costs of use and their periodicity. To derive the present-value total cost of use per functional unit, the pertinent functions are solved as an equivalent periodical annuity using continuous compounding (Hastings, 2010).

Using one typical example, the market-price estimate $P_{\mathrm{B}}$ of a benchmark product $\mathrm{B}$, expected lives $\Lambda_{\mathrm{A}}$ and $\Lambda_{\mathrm{B}}$ of both the new and benchmark products, cost of unit replacement $T$, the unit-production cost differential $\Delta C_{\mathrm{A}}$ of A versus $B$, the supplement mass $\mu$ of substance $\mathrm{Y}$ in unit of product $\mathrm{A}$, the relative performance-based value premium $\Pi_{\mathrm{A}}$ of $\mathrm{A}$ versus $\mathrm{B}$, and the continuously compounded periodical discount rate $r$ provide a generalized $P_{\mathrm{Y}}$ model-price solution as in:

$$
P_{Y} \leq\left[\left(P_{B}+T e^{-\Lambda_{B} r}\right) \frac{\left(1-e^{-\Lambda_{A} r}\right)\left(1+\Pi_{A}\right)}{\left(1-e^{-\Lambda_{B} r}\right)}-P_{B}-\Delta C_{A}-T e^{-\Lambda_{A} r}\right] / \mu
$$

This model component is then used for two distinct purposes. In the first instance, it facilitates a value-based analysis of innovation for particular applications, identifying and quantifying corresponding benefits and risks over the whole product life cycle. Two such cases are presented in section Results. Furthermore, the component is integrated in the dynamic model, whose description follows, and which provides an economic assessment of the nanoparticle production plant.

\section{Assessing the Production Process}

As suggested by numerous studies (Pindyck, 1982; Fuss \& Vermeulen, 2008; Banker et al., 2014), the fundamental risk factor for the economic viability of a manufacturing plant is market demand for its product; market prices can then be reasonably considered as its proxy. Assuming $N$ materials that would potentially be produced by the nanomaterials manufacturing plant, an equal number of prices accordingly needs to be estimated in order to perform its proper valuation. Depending on the particular material, 
prices can be estimated either directly, making projections of commodity nanomaterial markets, or recursively, using a LCC model, as illustrated in Figure 1.

Under static assumptions, i.e. using a fixed set of projected market prices, the plant's overall viability would be inferred from establishing the existence, or nonexistence, of a break-even product portfolio. This would be done by calculating and ranking the contribution margin of each material that can possibly be produced. Using conventional costing criteria (Drury, 2007) it would then always be desirable to manufacture a material with a positive margin to full capacity, it would be undesirable to manufacture a material with no overhead coverage, and it might be efficient to manufacture a material with positive overhead coverage to achieve full capacity if it were combined with at least a minimal proportion of one achieving a positive margin that would ensure at least full overhead coverage.

Conventional capital budgeting for the plant thus becomes a trivial problem, provided the calculation of one or more materials were to indicate a positive margin with aggregate demand saturating full capacity, or, alternatively, if no such material were available with a sufficiently high demand projection.

However, static assumptions and calculation methods are clearly not adequate for assessing a project that relies primarily on nascent demand and faces competition for various new materials and applications, many of which offer extraordinary margins with an extremely high degree of risk. Moreover, scenario calculations suggest strong sensitivities in respect to critical valuation assumptions, such as growth. There also exists a number of relevant system feedbacks, most notably producers' responses to current demand and market prices.

This characteristic of the problem merits the use of a dynamic model solved by a parametric statistical simulation, i.e. a Monte Carlo model (Mun, 2006; Mordechai, 2011).

In its design it is postulated that the plant would be able to produce any of a number of various chemical substances with known characteristics. Production is sequential, satisfying current orders. For technological reasons (some nanoparticle solutions only maintain their desired properties for limited periods of time), no finished product inventory is maintained, the product being delivered immediately to industrial users for further processing into an end-product. Costs of switching are relatively very low and can thus be reasonably neglected.

For each simulation period and production item (i.e. material) market or model prices $\left({ }^{\mathrm{i}} P_{\mathrm{X}}\right.$ or $\left.{ }^{\mathrm{i}} P_{\mathrm{Y}}\right)$ are being generated using a parametrized stochastic process and, based on that particular material's simulated overhead coverage, available production capacity is sequentially allocated to optimize current net cash flow. At the end of each simulation run, the production plant's net present value $(N P V)$ over its whole useful life is calculated. Each simulation run thus consists of a unique chain of production decisions, which may possibly include termination of production as well as operating below full capacity.

Given the relatively very high annual production capacity of the plant, which for some materials actually exceeds current global consumption, the model contains demand constraints. These are either explicit (through demand projections for particular materials) or tested against implied benchmarks, calculated as a result of sensitivity analyses.

\section{Results}

\section{NAI for Self-Cleaning Coating}

Self-Cleaning Coatings (SCC) are one typical application of nanomaterials in protective surface coating. Titanium dioxide $\left(\mathrm{TiO}_{2}\right)$ or other nanoparticles are added to various coating substances to enhance the level of surface hydrophobicity, resulting in a dramatic reduction in the need for surface maintenance (Som et al., 2011; Babaizadeh \& Hassan, 2013; Ferrari et al., 2015).

The main rationale for using SCC relates to substantial savings achieved in periodical surface cleaning over its useful life. It is thus possible to compare projected total costs of a particular paint being developed by a commercial producer and using the nanocomponent with conventional paint sold by the same producer and commonly used for the same purpose, i.e. the surface coating of metal constructions such as masts and bridges.

The functional unit of comparison will be one square metre of coating providing protection for one year. From the perspective of application, i.e. besides the self-cleaning property, both paints have similar characteristics, including their useful lives, cost of application and cost of liquidation. It is therefore possible to base the analysis primarily on cost differentials between the two products, rather than taking a full-cost approach.

The cash flow differentials are broken down over their respective time horizons, with the main differential item representing periodical maintenance savings ensuing from the use of the SCC technology based on a nanoparticle supplement to the paint solution. All relevant model variables are summarized in Table 1, with two separate scenarios considered, corresponding to high- and low-cost assumptions on labour costs from a European perspective (FedEE, 2016). Namely, Scenario I implies labour costs of approximately $€ 2.50$ per hour (i.e. the Czech or Hungarian minimum wage for unskilled labour), while Scenario II implies $€ 10$ per hour (i.e. the U.K. or Belgian rate).

Table 1

SCC vs. Conventional Paint Model Variables

\begin{tabular}{|l|c|c|c|}
\hline \multicolumn{1}{|c|}{ Item Description } & $\begin{array}{c}\text { Convent. } \\
\text { Paint }\end{array}$ & $\begin{array}{c}\text { SCC } \\
\text { Scenario I }\end{array}$ & $\begin{array}{c}\text { SCC } \\
\text { Scenario II }\end{array}$ \\
\hline $\begin{array}{l}\text { Product Cost (Excl. } \\
\text { Nanocomponent) [€] }\end{array}$ & 7.50 & 7.50 & 7.50 \\
\hline $\begin{array}{l}\text { Nanoparticle } \\
\text { Supplement [kg] }\end{array}$ & - & 0.0117 & 0.0117 \\
\hline $\begin{array}{l}\text { Nanocomponent Cost } \\
{[€ / \text { kg] }}\end{array}$ & - & 32.00 & 32.00 \\
\hline $\begin{array}{l}\text { Periodical Expense } \\
\text { Differential [€] }\end{array}$ & - & -1.50 & -6.00 \\
\hline Useful Life [Years] & 35 & 35 & 35 \\
\hline Discount Rate & $7 \%$ & $7 \%$ & $7 \%$ \\
\hline
\end{tabular}

Figure 2 compares the cost factors per functional unit for conventional paint and each of the SCC scenarios. The costs are broken down into three categories, including the cost of the paint base, the nanoparticle component (relevant for SCC only), and periodical maintenance (primarily labour). 


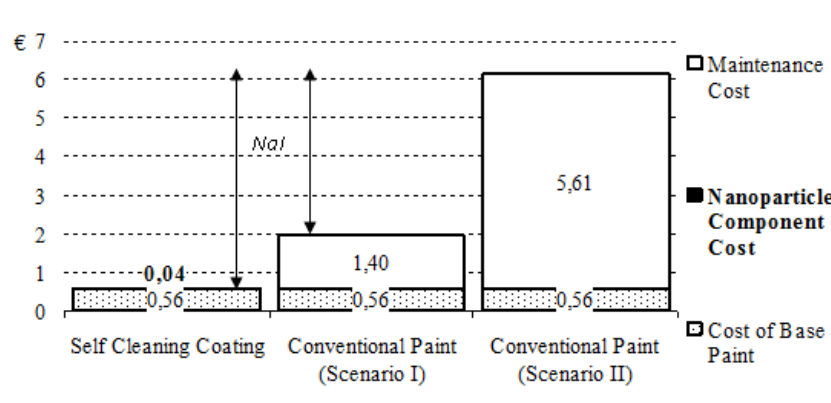

Figure 2. Functional Unit Cost Comparison for SCC

Any of the usage scenarios for SCC brings substantially lower costs per functional unit. This measure, which can be perceived as the Net Advantage to Innovating (NAI - a term adopted by the author in analogy to the commonly used Net Advantage to Merging or Net Advantage to Leasing, see e.g. Masoom, 2013, p. 356), amounts to ca $€ 1.50-€ 5.50$ per functional unit (protecting one square metre of construction for one year), which is substantial, compared to the cost of paint of just over $€ 0.50$.

Clearly, the difference stems from the maintenance (i.e. primarily labour) cost savings, and any increase in labour costs enhances this benefit. The impact of the nanoparticle component price seems minor.

In order to systematically analyse the risk factors, Figure 3 uses a tornado diagram to compare risk sensitivities. Their measures are calibrated against a delta of $10 \%$, i.e. they represent relative (percentage) changes in the value of $N A I$ due to a $10 \%$ increase or decrease in the value of the risk factor. Right-hand bars represent positive sensitivities, left-hand bars negative sensitivities.

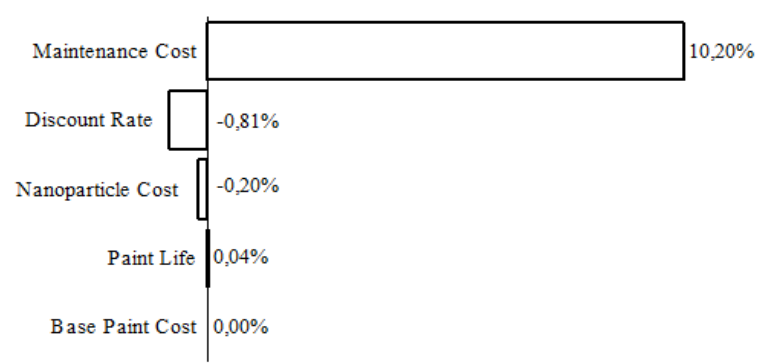

Figure 3. Sensitivity Analysis for SCC

This confirms the dominant role of maintenance costs, with a much lower impact of the discount rate. All other factors are negligible. Analysing breakeven, it can be shown that NAI falls to zero (thus making SCC uncompetitive) only assuming hourly labour costs of $€ 0.03$, which is an unrealistic scenario in developed countries.

One factor that the analysis in its present form does not consider, due to insufficient data, are potentially higher marketing costs for nanoparticle-based coating products, which may relate to environmental or workplace hazard concerns by the workers or the general public.

\section{NAI for Photocatalytic Coating}

Photocatalytic Coatings $(\mathrm{PhC})$ are solutions including $\mathrm{TiO}_{2}$ (titanium dioxide) nanoparticles that create a nonsolvent mineral surface coating with active photocatalytic properties removing microorganisms and air-borne pollutants as well as unpleasant odours from indoor or outdoor environments (Jaskova et al., 2013; Wei et al., 2014). The product being assessed here is a sanitary coating suitable for most plaster finishes, masonry or plasterboard on the interior or exterior of buildings. Its cleaning effect is activated upon illumination by daylight or artificial light with UV spectrum.

The functional benefit of $\mathrm{PhC}$ is clean air, which, being an economic externality, is virtually impossible to quantify in monetary terms. In some specific cases, a valuation of sorts is implied by regulatory intervention, but its rather arbitrary structures (e.g. flat-rate penalties based on ad-hoc limit transgression) effectively preclude a determination of the marginal cost of pollution, which might then possibly be compared to the marginal costs of its mitigation.

Accordingly, this assessment takes a different approach, focusing on the cost differential between $\mathrm{PhC}$ and an alternative, commonly used product, serving a similar purpose. The benchmark will be a mobile photocatalytic Air Purifier (AP) unit, and the functional unit will be cleaning one cubic metre of air for one year. Two extreme $\mathrm{PhC}$ usage scenarios are considered, distinguished by their need for artificial illumination (i.e. representative of encased indoor and outdoor use, respectively); Scenario I assumes energy consumption of 36W/24 hours/day, Scenario II assumes no energy consumption. Recurring AP costs constitute mainly energy, and bulb and filter replacements. The relevant model variables are summarized in Table 2.

Table 2

PhC vs. Air Purifier Model Variables

\begin{tabular}{|l|c|c|c|}
\hline \multicolumn{1}{|c|}{ Item Description } & Air Purifier & $\begin{array}{c}\text { PhC } \\
\text { Scenario I }\end{array}$ & $\begin{array}{c}\text { PhC } \\
\text { Scenario II }\end{array}$ \\
\hline $\begin{array}{l}\text { Product Cost (Excl. } \\
\text { Nanocomponent) }[€]\end{array}$ & $1,625.00$ & 822.00 & 822.00 \\
\hline $\begin{array}{l}\text { Nanoparticle } \\
\text { Supplement [kg] }\end{array}$ & - & 0.10 & 0.10 \\
\hline $\begin{array}{l}\text { Nanocomponent Cost } \\
{[€ / \mathrm{kg}]}\end{array}$ & - & 32.00 & 32.00 \\
\hline Periodical Expense [€] & 144.00 & 28.00 & 0.00 \\
\hline Useful Life [Years] & 10 & 5 & 5 \\
\hline Discount Rate & $7 \%$ & $7 \%$ & $7 \%$ \\
\hline
\end{tabular}

Figure 4 summarizes the costs per functional unit for the Air Purifier and each of the PhC scenarios. The costs are broken down into three categories: installation/painting (including also bulbs and filters for AP, labour for $\mathrm{PhC}$ ), the nanoparticle component (for $\mathrm{PhC}$ only), and power consumption.

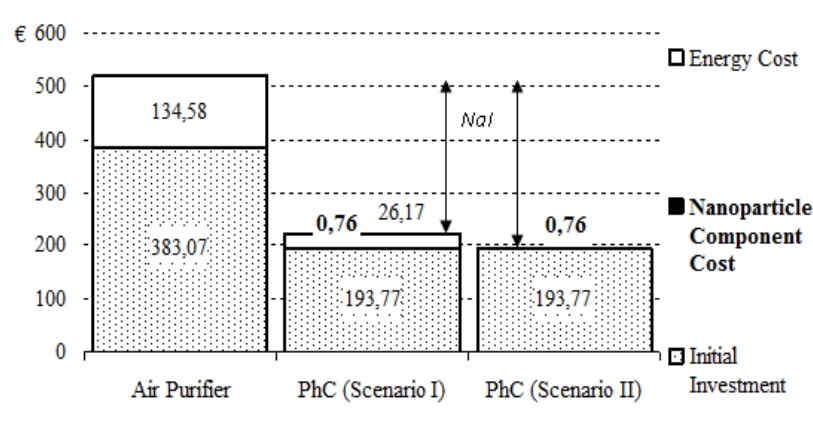

Figure 4. Functional Unit Cost Comparison for PhC 
Any of the usage scenarios for $\mathrm{PhC}$ results in substantially lower costs per functional unit. The NAI amounts to cca $€ 300$ per functional unit (cleaning one cubic metre of air for one year), roughly equal to one half of the cost of using the conventional AP.

There are two primary cost components determining the NAI: the acquisition cost and power consumption. The second item is straightforward to interpret: Even the most intense artificial illumination of the $\mathrm{PhC}$ uses much less energy than operating the AP, which means that any potential growth in electricity prices would increase the NAI further. More challenging is the former one, due to its dependency on useful life assumptions of both the $\mathrm{PhC}$ and the AP, as well as on their initial costs. The impact of the nanoparticle component price is negligible.

All sensitivities are illustrated by Figure 5, similarly to Figure 3.

\begin{tabular}{|c|c|c|c|c|}
\hline \multicolumn{3}{|c|}{ Paint Life } & & \multirow[t]{2}{*}{$10,80 \%$} \\
\hline$-10,30 \%$ & \multicolumn{2}{|c|}{ Air Purifier Life } & & \\
\hline & \multicolumn{2}{|c|}{ Air Purifier Cost } & & $9,26 \%$ \\
\hline \multicolumn{3}{|c|}{ Energy Cost } & & \multirow[t]{2}{*}{$7,88 \%$} \\
\hline & Labour Cost & $-3,43 \%$ & \multirow{3}{*}{$2,05 \%$} & \\
\hline \multicolumn{3}{|c|}{ Discount Rate } & & \\
\hline & Nanoparticle C & $-0,05 \%$ & & \\
\hline
\end{tabular}

Figure 5. Sensitivity Analysis for $\mathrm{PhC}$

Intuitively, one can envision medium-term scenarios where the market prices of APs would decrease, due to e.g. technological innovation, while labour costs would increase; at the same time the innovated APs may have increased useful lives and $\mathrm{PhCs}$ (which still have little empirical history) may turn out to have a shorter useful life than projected.

Two such scenarios that would result in breakeven situations are shown in Table 3. Either of these scenarios clearly seems to be extremely unlikely (including the implicit assumption of adverse factors' perfect correlation), which implies a very high probability of positive NAI for $\mathrm{PhC}$.

Table 3

Break Even Analysis for PhC

\begin{tabular}{|l|c|c|c|c|}
\hline Scen. & $\begin{array}{c}\text { PhC Useful } \\
\text { Life }\end{array}$ & $\begin{array}{c}\text { AP Useful } \\
\text { Life }\end{array}$ & AP Cost & $\begin{array}{c}\text { Energy } \\
\text { Cost }\end{array}$ \\
\hline A & $-30 \%$ & $+30 \%$ & $-30 \%$ & 0 \\
\hline B & $-20 \%$ & $+20 \%$ & $-20 \%$ & $-40 \%$ \\
\hline
\end{tabular}

It is to be noted that the present analysis does not necessarily demonstrate the economic advisability of air cleaning, based on a full cost-benefit assessment. This is currently impossible due to a lack of externality costing, i.e. inclusion of Type 5 costs (Beaver, 2000). Strictly speaking, it is shown that $\mathrm{PhC}$ clearly outperforms the AP wherever its use would be considered.

\section{Valuation of Nanoparticle Production}

The simulation session described in the Research Methods section provides an empirical distribution function of $N P V$ values as in Figure 6.

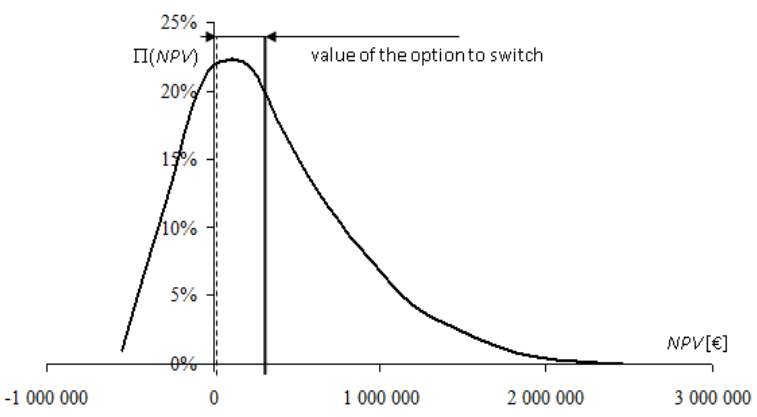

Figure 6. Production Plant Valuation

An analysis of this distribution can then be used to properly assess the value of the project and its risk (Vlachy $\&$ Freiberg, 2014). This result contrasts with the static projection (shown as a dashed line in Figure 6), yielding a single deterministic $N P V$, which is clearly unrealistic, not speaking about its outsize sensitivities to assumptions on particular valuation factors, such as the growth rates of particular parameters.

A particular competitive advantage of the hydrothermal synthesis-based nanoparticle-production process is its flexibility to switch production of various materials, which is a feature that may generally enhance the value of a project significantly (Nembhard \& Aktan, 2009; Bouasker \& Prigent, 2012). A number of authors, including Dixit and Pindyck (1994) or Schwartz and Trigeorgis (2001), denote such flexibility within projects as a real option, referring to a methodology whose theory postulates that the value of any real option increases with a) the volatility of the underlying assets and b) its time to expiry. In this case, both factors feature significantly. Accordingly, the mean $N P V$ of the simulation substantially exceeds the conventional $N P V$ estimate, due to its inclusion of the option to switch. Furthermore, the distribution is strongly positively skewed, which suggests favourable risk-management features of the project due to the probability of extreme profits being considerably higher than that of extreme losses (Brockett \& Kahane, 1992; Taleb \& Douady, 2013).

\section{Conclusions}

The industry of nanomaterials, their production and application is characterized by ongoing innovative processes at all stages of the product cycle. In terms of conventional financial analysis, this makes any specific projections extremely unreliable, with essential parameters, such as growth, subject to a high degree of risk, and the underlying processes impacted by multiple feedbacks. Meaningful results can thus only be produced using methods that take these factors into account. Specifically, we have developed a recursive form of life cycle costing to establish benchmark model prices, and used statistical simulation to capture relevant risk factors. This has facilitated valuation both from the end-users' point of view, as well as that of investors in different segments of the industry.

The cases presented in this paper show that both nanoparticle-based coating technologies constitute extremely valuable innovations, with robust estimates of a high Net Advantage to Innovation (NAI). However, the component impact of the nanoparticle cost is minuscule, 
which suggests that the innovation rent would be extracted by end-product innovators, which are frequently small and medium-sized companies, rather than material-production innovators. The strategies that can possibly be undertaken by materials producers to address this issue include some form of vertical integration, product quality or brand segmentation and, to an extent, production flexibility. In terms of publicly funded industrial policy, some form of support for nanomaterial-production research seems to be merited, as it would not jeopardize existing commodity producers, while enhancing the range of available materials for smaller or less capital-equipped product-innovating enterprises. It is also shown that the actual value of the hydrothermal synthesis-based nanoparticle manufacturing plant will be substantially higher than that calculated by conventional capital budgeting methods. This difference arises from the real option to switch. Its considerable value is determined primarily by two factors. The one is a very high degree of risk in the demand for a broad range of materials and end-products, which, furthermore, is largely uncorrelated. The other one is this particular production technology's capability of swift response to continuously arising new business opportunities, thus, at least temporarily, claiming some of the sizeable innovation rent associated with the placement of new nanoparticle-based products in the competitive global market.

The approach taken to resolve this particular problem indicates that creative analytical methods will generally be needed to properly assess investments in new technologies and business opportunities linked to innovation.

\section{References}

Arend, R. J. (2013). The Business Model: Present and Future - Beyond a Skeumorph. Strategic Organization, 11, 390-402. https://doi.org/10.1177/1476127013499636

Artto, K. A. (1994). Life Cycle Cost Concepts and Methodologies. Journal of Cost Management, 8(4), 28-32.

Azzopardi, B., Emmott, C. J. M., Urbina, A., Krebs, F. C., Mutale, J., \& Nelson, J. (2011). Economic Assessment of Solar Electricity Production from Organic-Based Photovoltaic Modules in a Domestic Environment. Energy \& Environmental Science, 4(10), 3741-3753. https://doi.org/10.1039/c1ee01766g

Babaizadeh, H., \& Hassan, M. (2013). Life Cycle Assessment of Nano-Sized Titanium Dioxide Coating on Residential Windows. Construction and Building Materials, 40, 314-321. https://doi.org/10.1016/j.conbuildmat.2012.09.083

Banker, R. D., Byzalov, D., \& Plehn-Dujowich, J. M. (2014). Demand Uncertainty and Cost Behavior. Accounting Review, 89(3), 839-865. https://doi.org/10.2308/accr-50661

Beaver, E. (2000). LCA and Total Cost Assessment. Environmental Progress, 19(2), 130-139. https://doi.org/10.10 02/ep.670190212

Bouasker, O., \& Prigent, J. L. (2012). Corporate Investment Choice and Exchange Option Between Production Functions. International Journal of Business, 17(2), 141-151.

Boussabaine, A., \& Kirkham, R. (2004). Whole Life-Cycle Costing: Risks and Risk Responses. Oxford: Blackwell Publishing. https://doi.org/10.1002/9780470759172

Brockett, P. L., \& Kahane, Y. (1992). Risk, Return, Skewness and Preference. Management Science, 38(6), 851-866. https://doi.org/10.1287/mnsc.38.6.851

Carlsson, B., Taylor, D., Hogland, W., \& Marques, M. (2007). Design of Functional Units for Products by a Total Cost Accounting Approach. VINNOVA Report VR 2007:01. University of Kalmar.

Charitidis, C. A., Georgiou, P., Koklioti, M. A., Trompeta, A., \& Markakis, V. (2014). Manufacturing Nanomaterials: From Research to Industry. Manufacturing Review, 1(11). http//:doi.dx.org/10.1051/mfreview/2014009

Christensen, C. (1997). The Innovator's Dilemma. Cambridge: Harvard Business School Press.

Clifton, M. B., Townsend, W. P., Bird, H. M. B., \& Albano, R. E. (2003). Target Costing: Market Driven Product Design. Boca Raton: Taylor and Francis.

Day, G. S. (2007). Is It Real? Can We Win? Is It Worth Doing? Managing Risk and Reward in an Innovation Portfolio. Harvard Business Review, 85(12), 110-120.

Dhillon, B. S. (2010). Life Cycle Costing for Engineers. Boca Raton: Taylor and Francis.

Dixit, A. K., \& Pindyck, R. S. (1994). Investment Under Uncertainty. Princeton: Princeton University Press.

Drury, C. (2007). Management and Cost Accounting. Boston: Cengage.

Dunne, P. W., Starkey, C. L., Gimeno-Fabra, M., \& Lester, E. H. (2014). The Rapid Size- and Shape-Controlled Continuous Hydrothermal Synthesis of Metal Sulphide Nanomaterials. Nanoscale, 6, 2406-2418. https://doi.org/10.1039/ C3NR05749F

Emblesvag, J. (2003). Life-Cycle Costing: Using Activity-Based Costing and Monte Carlo Methods to Manage Future Costs and Risks. Hoboken: John Wiley.

FedEE (2016). Review of Minimum Wage Rates [online]. Federation of International Employers. Available at: http://www.fedee.com/pay-job-evaluation/minimum-wage-rates/ [cited 15 June 2016]

Ferrari, A. M., Pini, M., Neri, P., \& Bondioli, F. (2015). Nano-TiO2 Coatings for Limestone: Which Sustainability for Cultural Heritage? Coatings, 5(3), 232-245. https://doi.org/10.3390/coatings5030232 
Fuss, C., \& Vermeulen, P. (2008). Firms' investment decisions in response to demand and price uncertainty. Applied Economics, 40(18), 2337-2351. https://doi.org/10.1080/00036840600959909

Gupta, Y., \& Chow, W. S. (1985). Twenty-Five Years of Life Cycle Costing - Theory and Applications: A Survey. International Journal of Quality \& Reliability Management, 2(3), 51-76. https://doi.org/10.1108/eb002854

Hansen, S. F., Heggelund, L. R., Besora, P. R., Mackevica, A., Boldrin, A.,\& Baun, A. (2016). Nanoproducts - What is Available to European Consumers? Environmental Science: Nano, 3(1), 169-180. https://doi.org/10.1039/C5EN00182J

Hastings, N.A.J. (2010). Physical Asset Management. London: Springer. https://doi.org/10.1007/978-1-84882-751-6

Jaskova, V., Hochmannova, L., \& Vytrasova, J. (2013). TiO2 and ZnO Nanoparticles in Photocatalytic and Hygienic Coatings. International Journal of Photoenergy, Art. ID 795060. https://doi.org/10.11 55/2013/795060

Masoom, K. (2013). The Entrepreneur's Dictionary of Business and Financial Terms, Singapore: Trafford.

Molloy, J. C., Chadwick, C., Ployhart, R. E., \& Golden, S. J. (2011). Making Intangibles "Tangible" in Tests of ResourceBased Theory: A Multidisciplinary Construct Validation Approach. Journal of Management, 37(5), 1496-1518. https://doi.org/10.1177/0149206310394185

Mordechai, S. (2011). Applications of Monte Carlo in Science and Engineering. The Hague: InTech. https://doi.org/10.5772/1954

Mun, J. (2006). Modeling Risk: Applying Monte Carlo Simulation, Real Options Analysis, Forecasting and Optimization Techniques. Hoboken: John Wiley.

Munn, A. S., Dunne, P. W., Tang, S. V. Y., \& Lester, E. H. (2015). Large-scale Continuous Hydrothermal Production and Activation of ZIF-8. Chemical Communications, 51(64), 12811-12814. https://doi.org/10.1039/C5CC04636J

Nembhard, H. B., \& Aktan, M. (2009). Real Options in Engineering Design, Operations, and Management. Boca Raton: Taylor and Francis. https://doi.org/10.1201/9781420071702

Park, C. S., \& Herath, H. S. B. (2000). Exploiting Uncertainty - Investment Opportunities as Real Options: A New Way of Thinking in Engineering Economics. The Engineering Economist, 45(1), 1-36.

Pindyck, R. S. (1982). Adjustment Costs, Uncertainty, and the Behavior of the Firm. The American Economic Review, 72(3), 415-427.

Rebitzer, G., \& Seuring, S. (2003). Methodology and Application of Life Cycle Costing. The International Journal of Life Cycle Assessment, 8(2), 110-111. https://doi.org/10.1007/BF02978436

RNCOS (2015). Global Nanotechnology Market Outlook 2022. Dubai: RNCOS Business Consultancy Services.

Sakurai, M. (1989). Target Costing and How to Use It. Journal of Cost Management, 3(2), 39-50.

Schwartz, E. S., \& Trigeorgis, L. (2001). Real Options and Investment under Uncertainty. Cambridge: MIT.

Shyman (2016a). Sustainable Hydrothermal Manufacturing of Nanomaterials [online]. Brussels: EC Cordis. Available at: http://cordis.europa.eu/project/rcn/103330_en.html [cited 15 March 2016]

Shyman (2016b). Sustainable Hydrothermal Manufacturing of Nanomaterials [online]. University of Nottingham. Available at: http://www.shyman.eu [cited 15 March 2016]

Som, C., Wick, P., Krug, H., \& Nowack, B. (2011). Environmental and Health Effects of Nanomaterials in Nanotextiles and Facade Coatings. Environment International, 37, 1131-1142. https://doi.org/10.1016/j.envint.2011.02.013

Stieberova, B., Zilka, M., Ticha, M., Freiberg, F., \& Hosek, J. (2014). Comparative Study of Nanoparticle Production Technologies Focused on Environmental Aspects., In NANOCON 2014 Conference Proceedings. Ostrava: Tanger.

Sun, H., Deng, J., Qiu, L., Fang, X., \& Peng, H. (2015). Recent Progress in Solar Cells Based on One-Dimensional Nanomaterials. Energy \& Environmental Science, 8, 1139-1159. https://doi.org/10.1039/C4EE03853C

Taleb, N. N., \& Douady, R. (2013). Mathematical Definition, Mapping and Detection of (Anti)Fragility. Quantitative Finance, 13(11), 1677-1689. https://doi.org/10.1080/14697688.2013.800219

Ticha, M., Zilka, M., Stieberova, B., \& Freiberg, F. (2016). Life Cycle Assessment Comparison of Photocatalytic Coating and Air Purifier. Integrated Environmental Assessment and Management, 12(3), 478-485. https://doi.org/10.1002/ieam.1786

Treacy, P. (2012). Valuing Innovation. Journal of Intellectual Property Law \& Practice, 7(11), 773. https://doi.org/10.1093/jiplp/jps170

Vlachy, J. (2009). Strategie podniku a financni teorie (Corporate Strategy and Financial Theory). Politicka ekonomie, 57(2), 147-162. https://doi.org/10.18267/j.polek.678

Vlachy, J., \& Freiberg, F. (2014). Deriving an Economic Model for the Production of New Materials. Applied Mechanics and Materials, 718, 3-8. https://doi.org/10.4028/www.scientific.net/AMM.718.3

Wei, X., Yang, Z., Tay, S. L., \& Gao, W. (2014). Photocatalytic TiO2 Nanoparticles Enhanced Polymer Antimicrobial Coating. Applied Surface Science, 290, 274-279. https://doi.org/10.1016/j.apsusc.2013.11.067

Woodward, D. G. (1997). Life Cycle Costing: Theory, Information Acquisition and Application. International Journal of Project Management, 15(6), 335-344. https://doi.org/10.1016/S0263-7863(96)00089-0

The article has been reviewed.

Received in November, 2016; accepted in December, 2017. 